\title{
What do we do now?: Responding to claims of germline gene editing in humans
}

\author{
Megan Allyse, PhD ${ }^{1}{ }^{1}$, Yvonne Bombard, $\mathrm{PhD}^{2}$, Rosario Isasi, JD, MPH${ }^{3}$, Marsha Michie, $\mathrm{PhD}^{4}$, \\ Kiran Musunuru, MD, PhD ${ }^{5}$ and Kelly E. Ormond, MS, LCGC
}

Genetics in Medicine (2019) 21:2181-2183; https://doi.org/10.1038/s41436-019-0492-3

\begin{abstract}
INTRODUCTION
In November 2018, the scientific community was rocked when He Jiankui, a Chinese biophysicist, claimed that he had overseen the birth of twin girls from embryos gene-edited at CCR5, a gene associated with resistance to HIV. ${ }^{1}$ He claimed that the infants were healthy and promised to provide sequencing data but declined to make the babies available for medical evaluation, ostensibly for their protection. (Chinese officials have since confirmed that a second pregnancy was initiated. See http://www.xinhuanet.com/english/2019-01/21/ c_137762633.htm. Accessed January 2019.)

Though controversial, research on in vitro germline gene editing to prevent disease is ongoing. Genetics researchers, clinicians, bioethicists, and patient stakeholders have worked for years toward consensus on the ethics of such work; building upon internationally enforced regulations around human subjects and clinical research, numerous professional bodies have issued guidance on the topic. (See the US National Academies of Sciences, Engineering, and Medicine (2017), the Nuffield Council on Bioethics (2018), and professional societies including the American College of Medical Genetics (2017), the American Society of Human Genetics (2017) (with endorsement by 11 additional professional societies globally), and the European Society of Human Genetics (2018)). While details differ, and some commentators continue to believe that germline editing should not be pursued at all, such statements generally support incremental, responsible translation based in robust science. Nevertheless, a researcher with no known clinical expertise appeared to have sidestepped international consensus on cautious translation and human subject research ethics.

Details of He's work emerged over several days. The project was largely kept secret from both He's own institution and government regulators, and was at least partially self-funded. ${ }^{2}$ The clinicians caring for the women
\end{abstract}

were apparently uninformed of the experiment ${ }^{3}$ and questions arose about the extent to which the study participants gave informed consent. While $\mathrm{He}$ consulted US-based geneticists and ethicists about his research, reports suggest that he did not reveal that he was moving forward with human trials. ${ }^{2}$ Shortly before the announcement, He's group published a proposed "ethical framework" for the use of germline gene editing ${ }^{4}$ but it's unclear whether any of the authors had expertise in research ethics or genetics and He's project appears to have violated many of his own ethical tenets. ${ }^{5}$ In short, it appeared that what was missing from this widely controversial application of gene editing technology was the guidance of actual clinical and ethical genetics professionals. Although He's project has subsequently been shut down, the genetics community remains faced with the question of what went wrong. And, more importantly, what do we do now?

\section{WHAT WENT WRONG}

As of 2018, international consensus statements held that while well-regulated research on human embryos may be permissible, reproductive applications should not be undertaken due to the lack of data on safety and efficacy and ongoing debates about moral and societal implications. ${ }^{6}$ Unintended consequences, including off-target variants and mosaicism, can cause unknown and difficult-to-measure harms. Instead, most researchers were focused on building a rigorous body of research to provide the foundation for concrete translational guidelines. Scientific and clinical communities have always relied extensively on such self-regulation; infringing guidelines often suffices to bar a researcher from funding, publication, and professional licensure. Moral condemnation by the scientific community had historically been seen as another effective sanctioning tool, or at least a powerful deterrent.

\footnotetext{
${ }^{1}$ Biomedical Ethics Research Program and Obstetrics and Gynecology, Mayo Clinic, Rochester, MN, USA; ${ }^{2}$ Li Ka Shing Knowledge Institute of St. Michael's Hospital, University of Toronto, Toronto, ON, Canada; ${ }^{3}$ J.T Macdonald Foundation Department of Human Genetics and Institute for Bioethics \& Health Policy, University of Miami Miller School of Medicine, Miami, FL, USA; ${ }^{4}$ Department of Bioethics, Case Western Reserve University School of Medicine, Cleveland, OH, USA; ${ }^{5}$ Departments of Medicine and Genetics, Perelman School of Medicine at the University of Pennsylvania, Philadelphia, PA, USA; ${ }^{6}$ Department of Genetics and Stanford Center for Biomedical Ethics, Stanford School of Medicine, Stanford, CA, USA. Correspondence: Megan Allyse (Allyse.megan@mayo.edu)
} 
In particular, available guidelines stressed that no experiment should proceed unless it addressed a compelling clinical need, which this one did not. ${ }^{8}$ Although the men He recruited were HIV positive, ${ }^{2}$ routine sperm washing during in vitro fertilization (IVF) treatment can remove the HIV virus, so it is unlikely the participants in He's project were ever at risk for HIV transmission during an IVF pregnancy. While He has stated that he sought to spare the children the pain of living with HIV, there are well-established means of preventing infection with HIV. And because the experiment was not based in widely replicated, multigenerational in vitro and animal model research, it is difficult to know whether it succeeded in conferring immunity. Furthermore, the data presented by He indicate that both embryos were mosaic for the genetic change intended, and at least one of the embryos had an unintended edit elsewhere in the genome. ${ }^{9}$ In a legitimate trial, it is highly likely that clinical geneticists and genetic counselors would have advised on the dangers of using such embryos reproductively.

From a human subjects research perspective, additional concerns arise. If research guidelines had been followed, an experienced clinical trialist would have been in charge of the study. Although He produced a document that claimed to be ethical approval from a review board, it contains no details of the trial and that body now claims it is fraudulent. ${ }^{10}$ There is no evidence that the experiment underwent legitimate human subjects review or that other protections that an ethics or regulatory review board would have required-including a data and safety monitoring board, a third-party consent monitor, and psychological assessment and support for the parent participants-were in place.

He distributed the study's consent document, but it makes no mention of the unknown medical consequences of his planned procedure. (Please see Supplemental Materials). He's statement that participants fully understood the procedure is questionable: if the clinicians who performed the IVF were unaware that the embryos had been genetically altered they could not have appropriately counseled participants on the implications and $\mathrm{He}$ has no known training in obtaining consent. ${ }^{3}$ It is not clear that the parents understood that reproductive germline gene editing was proscribed and knowingly implanting an embryo that is mosaic for a variant with unknown implications is highly controversial. ${ }^{11}$

HIV is highly stigmatized in Chinese society, and He has said that he initiated the study out of compassion for individuals living with the virus. Couples living with HIV can generally use standard IVF to avoid transmission, but Chinese law bans individuals with "sexual diseases" from accessing fertility treatments. ${ }^{12}$ Offering multiple cycles of expensive IVF and obstetric care, with the supposed promise of HIV negative children, to individuals who had no other reproductive options most likely constitutes undue inducement. In short, almost every tenet of responsible medical research appeared to have been set aside or fabricated.

\section{WHAT CAN WE DO NOW? \\ Emphasize good science}

Legitimate trials of somatic gene editing, and considerably more responsible in vitro studies in embryos, are being conducted under appropriate regulatory oversight. ${ }^{13} \mathrm{We}$ should not let rogue actors taint a field where the vast majority of scientists and clinicians have been transparent about their work. There are robust regulatory systems in place and the vast majority of the scientific community, in China and internationally, both work within them and work to improve them.

\section{Delegitimize substandard science}

Immediately after his announcement, there were calls to cancel He's scheduled talk at the International Summit on Human Gene Editing to avoid giving legitimacy to ethically problematic and regulatorily proscribed work. ${ }^{14}$ Others pointed out that the community could not assess the claimed work without public dissemination of the data. But giving a public platform-whether through scientific conferences or scientific publication-to such problematic research might appear to prioritize innovation over ethics. Alternative dissemination methods such as online repositories for prepublished data where peer review and comments are publicly available offer a compromise that allows scientists to scrutinize data without placing the imprimatur of legitimate scientific publication on unethical experiments. Nevertheless, the difficult question remains of whether scientific results obtained unethically should ever be accepted by the scientific community.

\section{Increase stakeholder engagement}

Genetics professionals can strengthen their ability to create and oversee responsible gene editing science by continuing to collaborate with patient and professional stakeholders. Honest, transparent conversations among the scientific community and current and future patients not only align scientific priorities with broader social goals, but help educate individuals about what constitutes legitimate clinical research. ${ }^{15}$ Greater engagement with stakeholder and patient groups might have not only applied more scrutiny to the intended application of gene editing but also done more to explain why it was not a legitimate application of the technology. ${ }^{9}$ Just as importantly, these conversations encourage trust and involvement in the scientific enterprise and help to avoid unrealistic expectations.

\section{Improve communication and reporting protocols}

Several scientists and ethicists have realized, in hindsight, that there were warning signs that $\mathrm{He}$ and his group were pushing the boundaries of acceptable research. ${ }^{2}$ Under current mechanisms, however, it is not clear how they could have reported concerns. Especially in an international context, there was at the time no centralized body with the remit to investigate potential breaches of research integrity, and professional societies do not have authority to scrutinize 
and sanction individual research projects. ${ }^{16}$ This is not to say, however, that the scientific community should be held harmless. Novel approaches have been suggested, including an international registry specific to gene editing research where studies could be entered prospectively, along with evidence of legitimacy and regulatory compliance. ${ }^{17}$ We hope that this case will also serve as an important lesson moving forward about the need to speak publicly about research misconduct. We have seen that it is possible to sidestep existing oversight and the scientific community should come together to innovate mechanisms for greater transparency, governance, and communication.

\section{CONCLUSION}

The lack of inclusion of qualified genetics professionals, policy experts, and ethicists in the planning and implementation of He's research is only one of its many problematic aspects. Still, we might optimistically assume that, had responsible clinical genetics professionals and ethicists been involved, the experiment would never have happened at all. The experience emphasizes the importance of coordinated and multidisciplinary research and maximal transparency in this area. Clinical genetics professionals have an understanding of the natural history of genetic disease and can more legitimately identify where gene editing may meet the threshold of clinical need. Genetics and bioethics researchers can advocate for the inclusion of perspectives from multiple viewpoints, including those of patients, families, and communities. Specialists in the ethical, legal, and social implications of genetics and human subject research can help to design robust, compliant protocols that advance the goals of clinical benefit, scientific discovery, and patient autonomy. We believe that with increased interdisciplinary collaboration, transparency, and public consultation there is a safe and ethical path forward for gene editing in humans. Rather than allowing this incident to drive our communities apart, we can take it as an opportunity to bring us even closer together.

\section{DISCLOSURE}

M.A. is supported by K01 HG009542. Y.B. is supported by an early career award from the Canadian Institutes of Health Research. The other authors declare no conflicts of interest.
Publisher's note: Springer Nature remains neutral with regard to jurisdictional claims in published maps and institutional affiliations.

\section{REFERENCES}

1. Marchione M. Chinese researcher claims first gene-edited babies. Associated Press. 26 November 2018. https://www.apnews.com/ 4997bb7aa36c45449b488e19ac83e86d. Accessed December 2018.

2. Begley S, Joseph A. The CRISPR shocker: how genome-editing scientist He Jiankui rose from obscurity to stun the world. Stat News. 17 December 2018. https://www.statnews.com/2018/12/17/crispr-shockergenome-editing-scientist-he-jiankui/. Last accessed 26 January 2019.

3. Normile D. Government report blasts creator of CRISPR twins. Science. 2019;363:328.

4. Jiankui, H, Ferrell, R, Yuanlin, C, Jinzhou, Q Draft Ethical Principles for Therapeutic Assisted Reproductive Technologies. The CRISPR Journal. 2018, https://www.liebertpub.com/doi/10.1089/crispr.2018.0051 .retract. Accessed 22 March 2019.

5. Molten M. Scientist who Crispr'd babies bucked his own ethics policy. Wired Magazine. 27 November 2018. https://mww.wired.com/story/hejiankui-crispr-babies-bucked-own-ethics-policy/. Accessed 22 March 2019.

6. Brokowski C. Do CRISPR ethics statements cut it?. CRISPR J. 2018;2:115-125.

7. Associated Press. Could anyone have stopped gene-edited babies experiment? Chicago Sun Times. 2 December 2018. https://chicago. suntimes.com/news/gene-edited-babies-experiment-what-could-havestopped/. Accessed 22 March 2019.

8. Cyranoski D, Ledford H. Genome-edited baby claim provokes international outcry. Nature. 2018;563:607-608.

9. Le Page M. CRISPR babies: more details on the experiment that shocked the world. New Scientist. 28 November 2018. https://www.newscientist. com/article/2186911-crispr-babies-more-details-on-the-experiment-thatshocked-the-world/. Accessed December 2018.

10. Associated Press. China says doctor who claimed using CRISPR to make gene-edited babies acted on his own. STAT News. 21 January 2019. https://www.statnews.com/2019/01/21/china-doctor-gene-editedbabies/. Accessed 22 March 2019.

11. Ethics Committee of the American Society for Reproductive Medicine. Transferring embryos with genetic anomalies detected in preimplantation testing: an Ethics Committee Opinion. Fertil Steril. 2017;107:5.

12. Wee $S-L, C h e n ~ E$. In China, gene-edited babies are the latest in a string of ethical dilemmas. The New York Times. 30 November 2018. https:// www.nytimes.com/2018/11/30/world/asia/gene-editing-babies-china. html. Accessed 22 March 2019.

13. Banks M. First CRISPR clinical trial begins in Europe. ScienceLine. 12 November 2018. https://scienceline.org/2018/11/first-crispr-clinical-trialbegins-in-europe/. Accessed 22 March 2019.

14. Isasi R, Kleiderman E, Knoppers BM. Genetic technology regulation Editing policy to fit the genome?. Science. 2016;351:337-339.

15. Burall S. Rethink public engagement for gene editing. Nature. 2018:555:438-439.

16. Choi C, Marchione M. Chinese scientist told US Nobelist about gene-edited babies. Associated Press. 2019. https://apnews.com/ 3f3bdc73e7c84fe685f2813510329d62. Accessed January 2019.

17. Editorial Board of Nature Magazine. How to respond to CRISPR babies. Nature. 2018;564:5 